\title{
A new heat exchange unit
}

\author{
PAUL MARCHAND AND LOUIS DU PLESSIS
}

\begin{abstract}
From the Department of Thoracic Surgery and the Cardio-vascular Research Unit, Johannesburg General Hospital and University of the Witwatersrand
\end{abstract}

Many heat exchange units are produced commercially. All function on the principle of a heatconducting membrane interposed between the circulating blood and the warming or cooling medium. Given optimal circulation of the blood and refrigerant and standard heat conduction properties of the membrane, the efficiency of the heat exchange unit will depend upon the surface area available for heat transfer and the thinness of the film of blood exposed. Increased efficiency would result if every component of the blood made contact with the cooling surface during a single circulation. This could be done by filming the blood to cell thickness or by agitation. Both methods are impracticable, the first because of the excessive pressure necessary to force the blood through a rigid unit, and the latter because of the foaming and damage to cells which is produced. Another approach is to allow the blood to flow slowly over an extensive cooling surface, but this requires a large unit and great quantities of priming blood. All heat exchange units must compromise between efficiency and practicability. The heat exchange surface should be as extensive as possible without requiring prohibitive volumes of priming blood. The blood should be filmed as narrowly and as smoothly as possible without producing excessive frictional resistance at physiological flow rates. These demands have necessarily resulted in a relative standardization of the efficiency of rigid units ; in the selection of equipment safety and simplicity should be considered. Safety depends on an excellent polish of the surfaces in contact with the blood, on a non-turbulent blood flow, and on the impossibility of admixture of the blood and the refrigerant. Simplicity should imply easy inexpensive manufacture and ready access to all surfaces in contact with the blood. Our Research Unit has produced two heat exchange units, one of which has already been described (Marchand, 1961).

\section{DESCRIPTION OF UNITS}

The characteristics of our first unit (Figs. 1 and 2) have been worked out by Miller, Wilson, and Isaacs
(1961). This unit is intended for low flow perfusions. The cooling surface area is $60 \mathrm{sq}$. in. ( $\pm 350 \mathrm{sq}$. cm.) and the priming volume is $80 \mathrm{ml}$. The cooling rate varies from 6,000 to $8,000 \mathrm{cal} / \mathrm{min}$. This unit was originally designed with varying clearances between the inner core and the cooling jacket but is now used only at flow rates of less than $1,000 \mathrm{ml} . / \mathrm{min}$., and the clearance has been standardized to $1 \mathrm{~mm}$. The instrument has been adopted by Creech for regional cancer perfusions and is manufactured in the United States of America by the Sigmamotor Company. We use it only for this purpose, although it is adequate for infant open-heart surgery.

Our second model (Fig. 3), which is made in two sizes, also films blood over a central core and has both the jacket and the core available for heat exchange. Blood is driven into the unit at the base and escapes from above, but from a level lower than the apex of the dome (Fig. 4). This is done so that air bubbles will rise to the uppermost point and escape into a trap, so providing for easy debubbling during priming, and dispensing with the need for a bubble trap in the arterial line. Because both are used for heat exchange, the clearance between core and jacket has been increased to $4.5 \mathrm{~mm}$. in the large unit and $2.5 \mathrm{~mm}$. in the smaller one. This has reduced the unit's resistance to the appropriate blood flow to negligible levels without impairing heat exchange efficiency. The smaller unit has a heat exchange surface of $\pm 1,200 \mathrm{sq} . \mathrm{cm}$. and a priming volume of $200 \mathrm{ml}$. and is suitable for flow rates up to $2,500 \mathrm{ml} . / \mathrm{min}$. The larger has $2,400 \mathrm{sq}$. $\mathrm{cm}$. of heat exchange surface and requires $550 \mathrm{ml}$. of priming blood and will cope with any required blood flow. These units are now used for all our human open-heart surgery.

\section{DISCUSSION}

The original torpedo-shaped unit used the inner core as a means of filming blood and exposing it to the outer jacket for heat transfer. The best feature of this design is that the blood flows in a linear manner through the unit so that turbulence is minimal. This is borne out by the fact that after many experimental and 32 human perfusions no foaming of blood was encountered, and it was never necessary to use a bubble trap in the distal arterial line. However, at flow rates above 1,000 $\mathrm{ml}$./min. the pressure gradient across the unit rises 


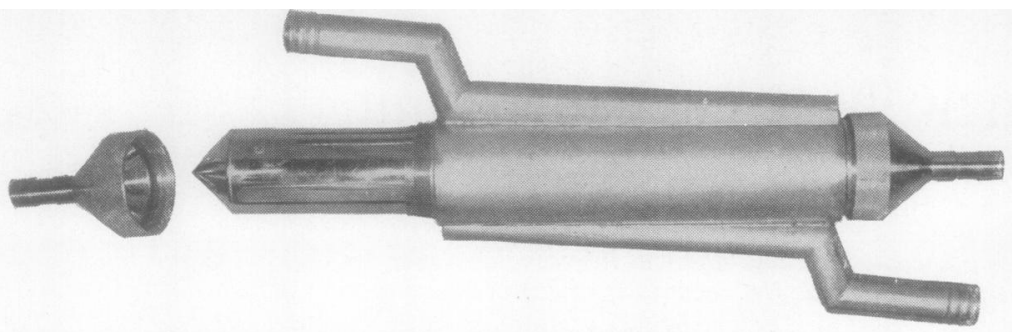

FIG. 1. Low flow heat exchange urit showing inner core which serves to film blood over the heat exchange surface of the outer jacket. Note the narrow space between core and jacket. (Reproduced with the permission of the Editor La - Semaine des Hôpitaux, Médecine dans le Monde, $37^{\circ}$ Année, No. 3-4, 1961, Pp. E97-105.)

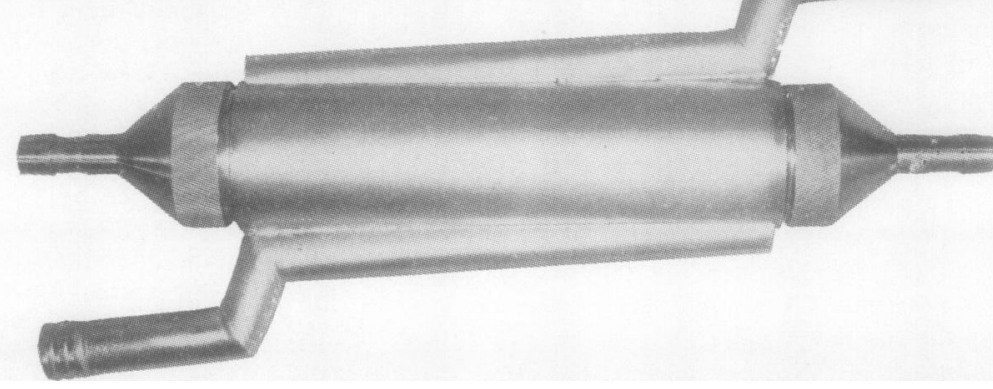

FIG. 2. Assembled unit. Refrigerant circulates around jacket only.

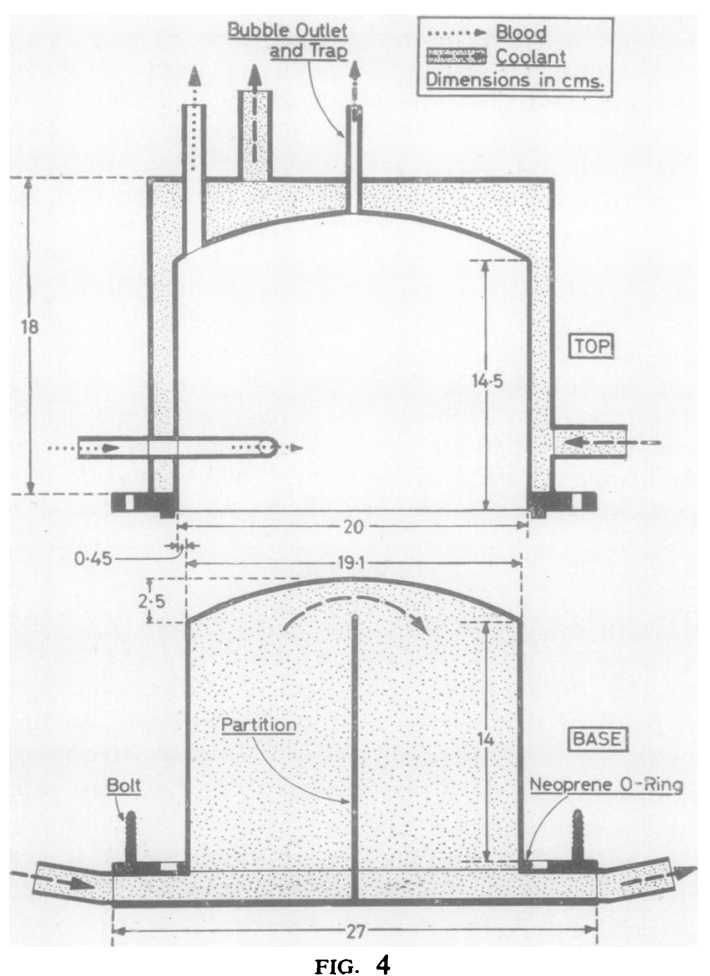

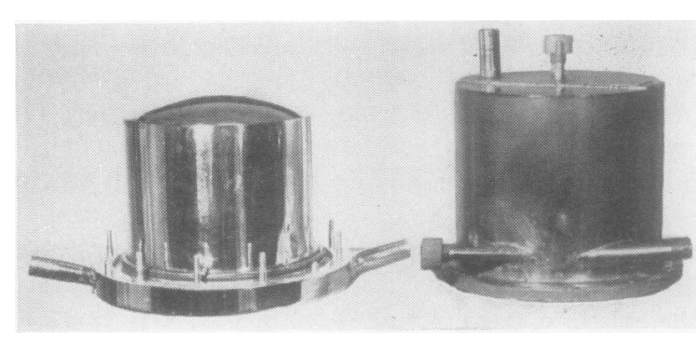

FIG. 3. New heat exchange unit unassembled. Inner core $\frac{D}{0}$ on left. Refrigerant circulates through both core and jacket. 三. Blood enters at base and escapes at top via connexions with $\mathrm{N}$ screw caps for holding $\frac{3}{8}$ in. Tygon tubing. Bubble trap is narrow gauge apical tube. Refrigerant circulates through $\mathrm{N}$ wide bore connexions fitting 1 in. Mayon tubing.

FIG. 4. Diagram of new heat exchange unit showing construction and dimensions. 
progressively. To overcome this, we and other teams in South Africa (Terblanche and Barnard, 1960) have used two or more units in parallel. This arrangement overcomes the problem of excessive proximal line pressure but introduces disadvantages of multiple connexions and increase in dead space. To avoid unnecessary connexions and high line pressures, which are the main cause of blood haemolysis, the second model was developed. With this model the blood is introduced parallel to and near the base of the unit, and escape is through a cannula at the top. This arrangement causes the blood to swirl around the unit from below upward. This, of course, does away with the more even flow obtained in the first model, and we anticipated that foaming of blood would occur. At the highest point of the dome, which is $2.5 \mathrm{~cm}$. above the outlet cannula, an additional vent is therefore provided which is connected to a chamber or length of tubing into which bubbles escape. Since 1960 more than 250 perfusions by various members of our department have been undertaken with this unit, and in prastice foaming has never occurred. However, the vent remains useful for evacuating air before perfusion is started.

The larger model was the first to be used, and, after many recordings, it was confirmed that no appreciable pressure gradient built up across the unit even at flow rates of more than $5,000 \mathrm{ml}$./ min. (Fig. 5). At high flow rates this model is efficient, and body temperatures can be adjusted rapidly and accurately by using a thermostatically controlled refrigerant and warming pump which circulates 40 litres of the medium through the unit per minute. At blood flow rates of under 1,500 $\mathrm{ml} . / \mathrm{min}$. warming and cooling are less efficient, probably due to channeling of the blood, so that blood streams directly from inflow to outflow, short-circuiting much of the heat exchange surface. This, together with the priming volume of $550 \mathrm{ml}$., which is excessive when a child is operated upon, made us decide to build an additional unit with a lesser clearance between core and jacket and a smaller priming volume. This unit is efficient and its resistance is negligible for flow rates of $2,500 \mathrm{ml} . / \mathrm{min}$.

With neither of the models is it possible for blood to mix with the refrigerant. The refrigerant circulates in a closed circuit through both core and jacket joined together externally with $\frac{1}{2}$ in. Mayon tubing. The basal Neoprene-O-ring is an efficient seal. If leakage should occur blood can only escape to the outside.

The surfaces in contact with blood are of highly polished stainless steel without nooks or crannies where blood can stagnate and clot. Cleaning is simple and accurate, and all surfaces can be directly inspected and scratches easily repolished. Apart from the inlet and outlet cannulae and bubble vent, there need be no welded joints on the surfaces exposed to blood, as both heat exchange surfaces could be made of sheet metal pressed over moulds. Our engineer has only done this with the inner core and has made the outer wall of tube metal to which the roof is welded.

We have cooled several patients with Fallot's tetralogy to temperatures of $10^{\circ} \mathrm{C}$. to $15^{\circ} \mathrm{C}$. without unduly prolonging the perfusion time. It is not, however, our present policy to cool routinely below $30^{\circ} \mathrm{C}$. We believe that low flow hypothermic perfusions are not ideal and that a by-pass is less complicated if it is possible to approach normothermic physiological flows even when the body temperature is reduced. Because of this policy a unit with minimal resistance is required. The addi-

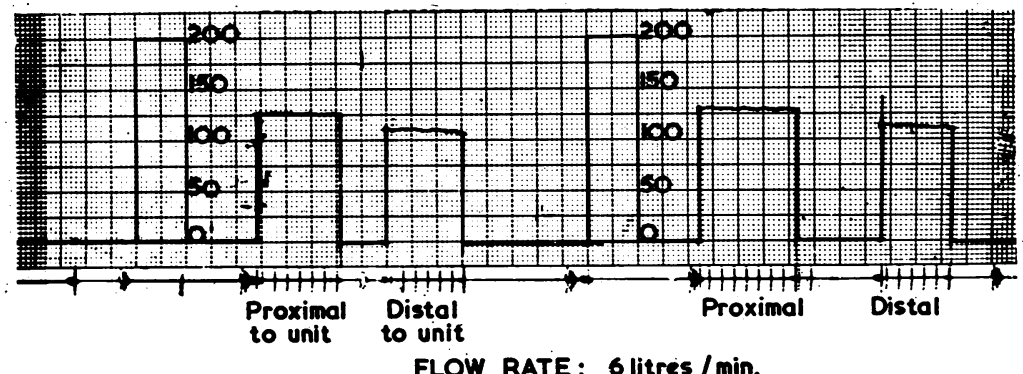

FIG. 5. Pressure tracings in the arterial line taken proximal and distal to the heat exchange unit at a flow rate of $6,000 \mathrm{ml}$./ $\mathrm{min}$. and a temperature of $32^{\circ} \mathrm{C}$. The gradient is $15 \mathrm{~mm}$. $\mathrm{Hg}$ and is due to the difference in levels between the inlet and outlet cannulae. The unit offers no resistance to blood flow. 
tion of low molecular weight dextran to the priming blood further reduces resistance to flow (Long, Sanchez, Varco, and Lillehei, 1961). If high flow perfusions are considered desirable notwithstanding the body temperature, then there are few indications for doing open-heart surgery under profound hypothermia. We therefore only drop the body temperature as a routine to $30^{\circ} \mathrm{C}$., but should circumstances, such as an uncomfortable bronchial circulatory flow or a complex abnormality, present which require the improved exposure provided by an arrested heart and circulation, then it is an advantage to be able to drop the body temperature rapidly and safely. The heat exchange units described allow this to be done.

The Cardio-vascular Research Unit of the University of the Witwatersrand is supported by funds from the C.S.I.R. (South Africa), the Wellcome Trust, and the Johannesburg City Council. We gratefully $\overrightarrow{\vec{F}}$ acknowledge the help received from these organizations.

The units are manufactured by Messrs. Bennington and Sons, P.O. Box 7014, Johannesburg. We are deeply indebted to Mr. C. Bennington, of this firm, who has given so much enthusiasm, time, and skill towards the final production of these units.

\section{REFERENCES}

Long, D. M., Sanchez, L., Varco, R. L., and Lillehei, C. W. (1961). The use of low molecular weight dextran and serum albumin as plasma expanders in extracorporeal circulation. Surgery, 50, 12.

Marchand, P. (1961). Extracorporeal circulation with hypothermia. Médecine dans le Monde, Sem. Hôp. Paris, 37, 3-4, E47.

Miller, M. W., Wilson, V. H., and Isaacs, F. (1961). Deep hypothermia : dynamic properties of heat exchangers and a thermotrol $\subseteq$ unit. $S$. Afr. J. med. Sci., 28, 11 .

Terblanche, J., and Barnard, C. N. (1960). Profound hypothermia using extracorporeal circulation without an artificial oxygenator: an experimental study. $S$. Afr. med. J., 34, 1003. 